\title{
UN VASO CON REPRESENTACIÓN DE BES EN LA PENÍNSULA IBÉRICA
}

\section{A VESSEL WITH A REPRESENTATION OF BES IN THE IBERIAN PENINSULA}

\author{
por \\ FRANCISCA VeláZQUEZ BRIEVA
}

RESUMEN El artículo intenta ofrecer algunas sugerencias sobre el origen, función, contexto y canales de distribución concernientes al vaso de alabastro con representación del rostro del dios egipcio Bes hallado en la tumba ${ }^{\circ} 17$ de la necrópolis del Cerro de San Cristóbal (Almuñécar, Granada), basándonos tanto en los datos que pueden ofrecernos los recipientes donde el dios es representado existentes en Egipto, como la información que pueda aportarnos el conjunto de vasos de alabastro dentro de los cuales este ejemplar se encuentra inmerso.

\begin{abstract}
The article tries to offer some suggestions about the origin, function, context and distribution channels concerning to the alabaster vessel with representation of Egyptian god Bes, found in the grave $n^{\circ} 17$ of "Cerro de San Cristóbal" (Almuñécar, Granada)'s necropolis. We have based our opinion so in the information offered by recipients where the god is represented in Egypt, as in the information supplied by similar alabaster vessels.
\end{abstract}

Palabras claves "Vasos Bes". Vasos alabastro. Necrópolis fenicias.

Key words "Bes jug". Alabaster Vessels. Phoenician necropolis.

\section{INTRODUCCIÓN}

En este artículo vamos a efectuar algunas consideraciones acerca del vaso de alabastro ${ }^{1}$ aparecido en la tumba $\mathrm{n}^{\circ} 17$ de la necrópolis fenicia del Cerro de San Cristóbal (Almuñécar, Granada), excavada como

1. Granada, M.A.P. 8332. 
de todos es sabido por el Dr. Pellicer en 1963, y cuyos resultados fueron publicados en ese mismo año (Pellicer 1963:24-30, figs. 25-26) ${ }^{2}$.

Se trata de un vaso de alabastro de $0,45 \mathrm{~m}$ de altura conteniendo restos humanos incinerados ${ }^{3}$, su forma es ovoide con cuello y borde ligeramente saliente y asas verticales de sección circular (fig.1) ${ }^{4}$. A la altura de las asas, en el centro del vaso, aparece grabada una cabeza del dios egipcio Bes $^{5}$, en medio de dos cartelas con el nombre y epítetos del faraón Osorkon II (870-847 a. C.) perteneciente a la Dinastía XXII (fig. 2).

La cara del dios es perfectamente reconocible: frontal, con orejas felinas, nariz chata y barba, debajo de la cual, está representado un collar del que penden una serie de colgantes triangulares. En la frente se distingue una especie de semicírculo rodeado de pequeñas rayitas que quizás forme parte, aunque no podemos estar seguros, del tocado, consistente en un alto penacho formado por cinco plumas, la del centro con una prolongación que llega hasta el arranque del cuello del vaso. Parece que el grabado intenta representar una máscara del dios colgada en el cuello de la jarra mediante una cuerda que se representa con esta prolongación incisa en el mismo.

La tumba $n^{0} 17$, por su posición en el conjunto de la necrópolis sería según J. Padró (1985:95) una de las más antiguas, fechable a comienzos del siglo VIII a. C. Sin embargo para I. Negueruela (1985:205 fig. 2) su cronología, basada en el estudio de la cerámica de barniz rojo, estaría dentro de las más modernas, entre el 635-615 a. C.

En este artículo haremos en primer lugar una reseña para intentar enmarcar iconográficamente la aparición del dios en este vaso de Almuñécar, dentro del que consideramos su contexto geográfico original, Egipto.

En segundo lugar reseñaremos los datos que pueden aportarnos otros vasos de alabastro aparecidos tanto en la misma necrópolis del Cerro de San Cristóbal, como en otros lugares peninsulares y extrapeninsulares.

Por último con los datos anteriores, intentaremos extraer algunas conclusiones sobre cuál pudo ser la finalidad y contexto inicial del vaso localizado en Almuñécar, así como en qué forma pudo arribar a las costas peninsulares.

\section{RECIPIENTES CON REPRESENTACIONES DEL DIOS BES EN EGIPTO}

El estudio de los vasos donde Bes aparece representado en Egipto es demasiado extenso para ser abordado en este breve artículo, no obstante intentaremos dar algunos ejemplos a fin de demostrar como la presencia del dios, y más concretamente la cabeza del mismo, era usual en recipientes egipcios, aunque podemos adelantar que hasta ahora no hemos encontrado nada comparable en calidad al vaso aquí estudiado. Así mismo

2. Los estudios sobre la necrópolis y sus materiales son abundantes destacando por su inmediatez la citada publicación de M.Pellicer (1963) y la noticia ofrecida por J. Maluquer de Motes (1963:57-62). Estudios posteriores son entre otros los efectuados por I. Gamer-Wallert (1973,1978), J. Padró (1983;1984; 1985; 1986; 1995) e I. Negueruela (1985:193-205; 1991:199-205).

3. Los estudios más concretos sobre este vaso son los realizados por M. Pellicer (1963:24 y 52), I. Gamer-Wallert (1978:38-39) y J. Padró (1985:94-97).

4. El tipo de vaso es perfectamente conocido en Egipto, donde aparece como mínimo desde la Dinastía XVIII con el nombre de hebenet; inicialmente de cerámica, fueron posteriormente copiados en piedra, ya en esta misma dinastía. Este tipo también es conocido en Palestina, lo que ha determinado que algunos autores como M. Pellicer lo denominen "jarra cananea". Esta forma de vaso de alabastro tiene múltiples paralelos tanto en otros vasos peninsulares aparecidos en la misma necrópolis del Cerro de San Cristóbal (ejemplares de las tumbas 11, 16 y uno fuera de contexto), como en Egipto, en la necrópolis real de Tanis (Montet 1951:165, Lám. CXXIX), Cartago (Cintas 1970: lám. XVIII) o Assur (Culican 1970:29).

5. La bibliografía sobre el dios Bes es muy abundante, en estudios iconográficos destacaríamos el ya clásico trabajo de $F$. Ballod (1913) y el más reciente de J.F. Romano (1989); en España contamos con estudios como los de J. Padró (1978:19-41) y $\mathbf{M}^{\mathrm{a}}$ J. López Grande (1988:12-24). 
trataremos de dilucidar cuál era su finalidad en este ámbito y el contexto en que dichos objetos suelen ser localizados.

Representaciones del dios sobre vasos se encuentran ya en Egipto en el Imperio Medio y Segundo Periodo Intermedio (c. 2040-1540 a. C.), reflejándose en estos ejemplares de forma clara los rasgos iconográficos del dios característicos de esta época, así el dios se presenta de cuerpo entero, frontal y portando serpientes en sus manos, según era usual en los denominados "cuchillos mágicos" (Altenmüller 1965), como aparece en la franja que decora un tipo cerámico realizado en fayenza hallado en Lisht, procedente de una tumba infantil (Friedman 1998) (fig. 3), al que se le ha adjudicado un uso como "biberón" 6.

En el Imperio Nuevo (c. 1540-1070 a.C.), el dios sigue siendo representado en diferentes recipientes, adoptando igualmente las variantes iconográficas que va adquiriendo a lo largo de este período. Así, probablemente de época de Amenhotep III existen ejemplares como la vasija de fayenza procedente de Gurob $^{7}$ (Petrie 1974 reimp.: lám. XVII, 9), en la que se representa al dios con la iconografía característica de este período, de cuerpo entero, alado y vestido, sujetando en sus manos símbolos como el $w d \underline{d} t$ (fig. 4).

Otro tipo de recipientes que asocian a Bes en su decoración son los contenedores de cohol, alguno de cuyos primeros ejemplares pueden asignarse, por las características iconográficas que presenta el dios, a comienzos de la Dinastía XVIII, como el proveniente de la colección Carnavon (Hayes 1959:192, fig. 107) que presenta en relieve la figura completa del dios en ambas caras (fig. 5). Estos contenedores gozarán de gran desarrollo durante toda la etapa faraónica, y en ellos Bes será ampliamente representado, adoptando en ocasiones el recipiente la forma de su cuerpo. En otras ocasiones es únicamente la cabeza del dios la que se asocia a vasos cosméticos, como las que se encuentran en forma de capiteles sobre dos columnas lotiformes en un ejemplar procedente de la tumba de Tutanjamon (Carter y Mace 1923). Sin embargo, estos tipos de recipientes no serán tratados en el presente artículo, ya que su función se aparta de la considerada para el vaso de Almuñécar.

También del Imperio Nuevo data la aparición de la cabeza de Bes asociada a vasijas, donde constituye parte integrante de su tapadera. Un ejemplo lo constituye un vaso realizado en caliza de carácter probablemente funerario, formando parte del ajuar de un escultor de época de Amenhotep III (c. 1387-1350) (Hayes 1959:277, fig. 169). Este tipo de asociación debió ser característica durante todo el Imperio Nuevo como podemos observar en relieves que representan grandes vasijas con cabezas de Bes en sus tapaderas, como el ejemplo existente en la TT 65 de Nebamon (Wreszinski 1988, lám. 224), o las representadas en templos como en el de Seti I en Karnak (Ballod 1913: 50, fig. 46) (fig. 6).

También se datan en la Dinastía XVIII, probablemente desde la época de Amenhotep III, un tipo de $\operatorname{vasos}^{8}$ donde existen representaciones muy sofisticadas del dios, las más características y en relación con nuestro estudio, presentan el rostro y, en ocasiones, un esbozo de los brazos del dios, dibujados y más comúnmente en relieve sobre el cuello de jarras usadas como contenedores de líquidos (Bruyère 1939:102, fig. 35) (fig. 7).

Queremos destacar que estos vasos que presentan el rostro del dios, comparten su protagonismo con ejemplares que presentan el rostro de la diosa Hathor. La aparición sobre el mismo tipo de recipiente de ambas divinidades en exclusividad, es uno de los motivos que parecen indicar su conexión con un ritual en el que los dos dioses se encontrarían implicados.

En el Imperio Nuevo estos vasos son casi exclusivos del área tebana, y aunque no es inusual su hallazgo en contextos funerarios, se encuentran fundamentalmente en lugares de habitación como en Deir el-Medina,

6. New York, MMA 1944. 44.4.4.

7. Oxford, Ashmoleam Museum, 1890.897.

8. Se trata de los denominados "Bes Jug" o "Bes-pot" en la bibliografía anglosajona, y que en este artículo designaremos "Vasos Bes". 
donde debido a las características de su decoración, y su aparición en las casas, autores como B. Bruyère (1939:103) o $\mathrm{M}^{\mathrm{a}} \mathrm{C}$. Guidotti (1983:37-38) se inclinan a pensar que no estarían destinados al uso cotidiano doméstico, sino al cultual, para libaciones y abluciones en ritos de carácter familiar, quizás en algún tipo de ritual alrededor del nacimiento. Su contenido, según la última autora, pudo haber sido agua o incluso leche, conectada con el fenómeno del nacimiento y la maternidad, y que en el caso de su aparición en tumbas tendría un carácter revivificador, de renacimiento tras la muerte, aunque hay que señalar que no hay nada probado respecto a la identidad del contenido.

Otros vasos decorados con máscaras de Bes se han localizado en Tell el-Amarna (Peet y Woolley 1923, lám. XLV:4) (fig. 8), y se encuentran también en la dinastía XX, entre los productos procedentes del sur representados en la tumba tebana $n^{\circ} 65$ perteneciente a Imasib, datada en el reinado de Ramses $\mathrm{X}$ (Bruyère 1939:95, n. 1).

Ya en el Tercer Período Intermedio (1070-664 a. C.), cuya cronología incluye el período en el que se dataría el vaso objeto de nuestro estudio, los "Vasos Bes" siguen existiendo, aunque se aprecia una evolución en su forma y en su decoración, que pasa de las más sofisticadas representaciones pintadas o casi tridimensionales del dios, a una plasmación con incisiones y arcilla de los rasgos estilizados del mismo, cuyo esquematismo se irá acrecentando a lo largo del período.

Sin embargo la cronología de estos "Vasos Bes" en la Dinastía XXII (945-715 a. C.), a la que aluden las cartelas del vaso que estamos considerando, no está suficientemente bien establecida. Para $\mathrm{M}^{\mathrm{a}} \mathrm{C}$. Guidotti (1983:33-65) que ha efectuado un completo catálogo de este tipo de vasos en la Baja Época, la tipología correspondiente a esta dinastía, el tipo A (fig. 9), tendría un carácter de transición entre los "Vasos Bes" del Imperio Nuevo y los que se atestiguan en la Dinastía XXIII-XV (fig. 10) continuando en la Época Saíta.

Este "tipo A" de $\mathrm{M}^{\mathrm{a}} \mathrm{C}$. Guidotti, se caracterizaría por poseer representada en la parte superior del vaso un rostro estilizado del dios realizado en relieve mediante la aplicación de arcilla, siendo completado en ocasiones con incisiones.

Otro autor que ha estudiado estos "Vasos Bes", P. Charvát (1980:46-52), es también partidario de la existencia de esta etapa de transición entre el Imperio Nuevo y la Época Saíta.

Desgraciadamente los ejemplos aportados por estos investigadores no pertenecen a contextos fiablemente datados, y otros autores consideran que su cronología debe ser rebajada. Así en las excavaciones de Enashia el-Medina (López Grande et alii 1995:104-105), los "Vasos Bes" (fig. 11), pueden incluirse en gran parte en el tipo A de Guidotti, pero los contextos de aparición son más tardíos, con una cronología de finales del siglo VIII y comienzos del VII a. C. Hay que destacar que en esta época el lugar de aparición de estos vasos son las tumbas, situándose a menudo cerca de la boca del difunto, anunciando lo que será una constante en la Época Saíta donde el vaso Bes alcanzará una gran difusión en los enterramientos.

A pesar de la dificultad para encontrar ejemplares bien datados durante la Dinastía XXII, consideramos que su pervivencia es segura, pudiendo deducirse que existe una continuidad durante el Tercer Período Intermedio, etapa en la cual tendría lugar un proceso de estilización y economía de recursos en la representación del dios, así como un cambio de contexto, que pasaría del uso ritual doméstico al funerario, probablemente con una finalidad similar, ayuda para el "nacimiento" en la otra vida, como queda ampliamente demostrado durante toda la Época Saíta, donde tanto "Vasos Bes" como amuletos que los reproducen acompañan los enterramientos de esta época en gran parte del territorio egipcio.

Por último, señalar que representaciones de Bes en vasos seguirán teniendo lugar en el Período Grecorromano, aunque sus características cambiarán fundamentalmente, hasta ofrecer la adaptación de un rostro del dios no estilizado y en ocasiones bifronte a la forma del recipiente (fig. 12), cuya finalidad parece estar más encaminada a contener perfumes. Este tipo de vasos parece perdurar incluso en el período copto 9

9. Se han encontrado ejemplares en enterramientos, alguno de cronología muy avanzada (Charvát 1980:51). 
Consideramos, pues, constatada la presencia en Egipto en el Tercer Período Intermedio de vasos donde se representa el rostro estilizado del dios y que ostentan fundamentalmente una finalidad funeraria conteniendo un líquido, quizás revivificador para el renacimiento tras la muerte, cuya identidad no está suficientemente demostrada.

\section{VASOS DE ALABASTRO}

En la necrópolis de Almuñécar el ejemplar donde Bes está representado, forma parte de un conjunto excepcional de veintiún vasos de alabastro ${ }^{10}$ (Pellicer 1963; Molina y Padró 1983:288-290; Molina y Bannour 2000: 1646) usados como urna cineraria, por lo que consideramos que el ejemplar objeto de nuestro estudio debe ser analizado dentro de este contexto, ya que algunos de estos vasos también ostentan cartelas de los faraones Osorkon II, (874-850) ${ }^{11}$, Takelot II (850-825) y Sheshonq III (825-773), todos pertenecientes a Dinastía XXII (siglos IX-VIII a. C.), así como inscripciones jeroglíficas ${ }^{12}$ que aportan interesantes datos y cuyas traducciones han sido publicadas por I. Gamer-Wallert (1973:401-408; 1978:24-45) y J. Padró (1983: 215-226; 1985:64-101;1986:526-529).

Aparte de los hallazgos del Cerro de San Cristóbal, otros vasos de alabastro han aparecido también en necrópolis. Existen ejemplares procedentes de Lagos ${ }^{13}$ (Aubet et alii 1991), Trayamar (Schubart y Niemeyer 1976:63-77), Jardín (López Malax-Echevarría 1971-73:29, fig. 12) y Cerro del Mar donde apareció una base de un vaso de alabastro.

También existen hallazgos de estos vasos en el litoral andaluz sin contexto exacto conocido, pero que podrían provenir de necrópolis. Así, en la provincia de Almería fue hallado un vaso en el Cerro de Montecristo, similar a los de Almuñécar (García Alfonso et alii 1999:64); a la provincia de Málaga pertenecen cuatro vasos procedentes de Torre del Mar $^{14}$ (Pérez Die 1976: 903-918) y el ejemplar de Churriana ${ }^{15}$ (Pérez Die 1983: 237-244), así como otros varios fragmentos pertenecientes a vasos de este tipo (Baena del Alcázar 1978: 159-163). En Cádiz también existen ejemplares tanto en la capital, un vaso reutilizado en época romana (García y Bellido 1970: 21-23), como en su provincia: el vaso de Barbate (Gómez Moreno 1958: 153, fig. 162) y el vaso aparecido el siglo pasado en el Puerto de Santa María (García y Bellido 1970: 11-15) ${ }^{16}$. Este último ejemplar presenta un especial interés para nuestro análisis por ser portador de una inscripción jeroglífica estudiada por I. Gamer-Wallert (1976:2 23-228).

10. De estos vasos, diecisiete fueron recuperados durante la excavación de 1962 y cuatro más posteriormente, formando el conjunto de vasos de este tipo más importante fuera de Egipto. A este conjunto se puede añadir el vaso de mármol gris con cartela de Apofis I que podría provenir también de esta necrópolis.

11. La cronología de la D. XXII es la ofrecida por E. Driotón y J. Vandier (1962:631) prácticamente confirmada por K. A. Kitchen (1986).

12. Vasos localizados en las tumbas $n^{\text {os }} .1$ y 15 , ya que la existente en el vaso perteneciente a la tumba $n^{\circ} 16$, por la mala calidad de sus signos, no ha sido todavía publicado.

13. Necrópolis probablemente relacionada con el poblado de Chorreras, donde se han encontrado dos tumbas de pozo, una conteniendo un vaso de mármol ónice con incineración.

14. Aquí fueron hallados varios vasos de alabastro en el siglo XVIII, hoy en el M.A.N. nos. 16801-16804, probablemente procedentes de la necrópolis arcaica del poblado de Toscanos, donde se han encontrado tumbas de pozo semejantes a las de Almuñécar.

15. Colección particular de D. Luis Arcos Cavajal. Este ejemplar fue encontrado al parecer junto con un vaso canopo egipcio, noticia que de confirmarse reafirmaría la teoría de la adquisición de vasos funerarios egipcios, aunque autores como J. Padró no lo cree probable (1995:150-151). Junto a este vaso parece que en el pasado pudieron existir otros cuatro vasos de alabastro más, de idéntica procedencia.

16. El ejemplar de Barbate y del Puerto de Sta. María pueden ser el mismo; García y Bellido (1970:13) piensa que se trata de piezas distintas, pero queda la posibilidad de que no sea así, según ha defendido $\mathrm{D}^{\mathrm{a}}$ Concepción Blanco. 
Dada la homogeneidad y exclusividad de estos vasos consideramos que el conocimiento de sus inscripciones, en cuya problemática no podemos entrar en profundidad por falta de espacio ${ }^{17}$, puede aportarnos datos para plantear alguna hipótesis acerca de su uso original, procedencia y camino recorrido hasta llegar a las costas peninsulares, datos que pueden ser considerados para el ejemplar que estamos aquí analizando.

Tras el estudio de estas inscripciones, tanto J. Padró como I. Gamer-Wallert están de acuerdo en establecer un origen egipcio para estos vasos, con una fecha de fabricación durante la Dinastía XXII; igualmente ambos abogan por que su contenido era vino de los oasis de Bahariya y Jargah, situados en el desierto líbico, zona principal del cultivo vinícola de Egipto.

Sin embargo existen diferentes opiniones sobre el contexto original de los vasos y la finalidad a la que pudieron estar destinados.

Para I. Gamer-Wallert, (1973:406-408; 1976:228) los vasos podrían pertenecer al ajuar funerario de tumbas egipcias de donde habrían sido expoliados, apuntando que un indicio a favor de su posible finalidad funeraria, con la cual estamos de acuerdo, es el calificativo que en el vaso de la tumba $n^{\circ} 1$ del Cerro de San Cristóbal se da el personaje como $\check{s} m s w$, término que significa acompañante, perteneciente al séquito de un rey o un príncipe; pero que también se da al muerto en los textos funerarios del Imperio Nuevo como acompañante de $r^{\complement}$ en su barca solar.

Así mismo otro indicio sería la repetida alusión que se hace en estas inscripciones al "ka" con el uso de la fórmula $n k 3 n$ " para el ka de..." usualmente utilizada para los fallecidos ${ }^{18}$, ya que aunque el "ka" formaba parte inseparable de la persona durante toda su vida, era éste el que permanecía en la tumba, de ahí la coherencia de que las ofrendas funerarias fueran a él referidas, lo que puede poner en conexión este vaso con ofrendas de vino al difunto.

El reaprovechamiento de vasos de alabastro con probable procedencia del saqueo de necrópolis antiguas, no es tampoco nada nuevo. M.A. Molinero (995:235) hace referencia a la existencia de vasos de alabastro con las cartelas de Pepi I y Pepi II, junto al material del Imperio Medio y Segundo Período Intermedio en las salas adyacentes a la entrada de la capilla K I de Kerma, material que este autor considera producto de un comercio de vasijas de piedra obtenidas mediante el saqueo de tumbas antiguas, por lo cual, si este comercio era posible en el Segundo Período Intermedio no hay razón para que no vuelva a ser fructífero en el Tercer Período Intermedio.

Este comercio explicaría que se puedan encontrar mezcladas formas con claros paralelos en el Predinástico, dinastías Tinitas o en el Imperio Medio, en contextos de enterramientos de fines del Tercer Período Intermedio como en Enasya el-Medina, donde parece que los enterramientos requieren la presencia de estos vasos, de los cuales a veces sólo se encuentra un trozo reutilizado (Molinero 1995:234) ${ }^{19}$.

17. En la actualidad nos encontramos realizando un estudio de las inscripciones jeroglíficas egipcias en la Península Ibérica, en el que esperamos ofrecer nuestro análisis de las inscripciones correspondientes a los vasos aquí considerados.

18. Aunque es lo usual, reconocemos que no es una fórmula que siempre presuponga que el "poseedor del Ka" esté muerto. Hemos localizado una inscripción en la tumba de Herkhuf (Sethe Urkunden I:120-131) en la que se hace referencia a una carta mandada por éste a Pepi II (VI Dinastía) dándole noticia de los artículos preciosos traídos para su Ka, cuando este faraón se encontraba vivo.

19. La reutilización de vasos funerarios egipcios también habría podido ser el motivo del hallazgo en la necrópolis del Cerro de San Cristóbal de un vaso característico de la D. XVIII (Granada, M.A.P. 8324) (Padró 1995:101), así como de un vaso con el nombre de Apofis I, faraón de la XV Dinastía (1600 a. C.), que aunque carente de contexto ha sido también localizado en Almuñécar. Igualmente se constata la presencia en esta zona del litoral andaluz de dos vasos canopos, como el que puede proceder de Churriana (Gamer-Wallert 1978:59-61; Pérez Die 1983:240-243), y un ejemplar de la colección Fernández Canivell (Gamer-Wallert 1972:267. 271), aunque también carecen de contexto, y han podido ser traídos a la Península recientemente; por lo que no pueden ser aportados como prueba. 
Esta teoría ya fue sostenida en los comienzos de la investigación por autores como J. Maluquer (1963: 59-60) que sugieren más concretamente su procedencia de la necrópolis real de Tanis, y a ella se han incorporado autores como I. Negueruela (1989: 200) y A. Ma Jiménez Flores (1996: 37-38) entre otros.

Sin embargo, J. Padró (1986:528) opina que estos vasos estaban desde su origen destinados a la exportación de vino de calidad, ya mediante el comercio, ya como regalos diplomáticos, aunque este uso no aclara su presencia en el litoral peninsular, puesto que la cronología de los faraones cuyas cartelas ostentan los vasos es bastante anterior a su deposición en las tumbas de los colonos fenicios. Este autor considera poco probable su procedencia del ajuar de ninguna tumba, ya que de los textos no se desprendería un carácter funerario.

Otro autor que ha hecho referencia a este tipo de vasos J. Leclant (1991:9-10) opina que sus ejemplares son muy característicos en Egipto donde pueden haber pertenecido al mobiliario real, interrogándose si pueden proceder de la necrópolis de Tanis, aunque dice desconocer en qué momento y en qué condiciones han salido de Egipto. Para este autor también cabe la posibilidad de que hayan podido servir para la exportación de productos de lujo destinados al comercio fenicio, o hayan podido formar parte del botín tomado por las tropas asirias en las campañas de la $1^{\mathrm{a}}$ mitad del siglo VII a. C. contra Egipto bajo Senaquerib, Assarhadon y Assurbanipal ${ }^{20}$.

Otra opinión al respectoes la de W. Culican (1970:29-32) que conecta los vasos de alabastro de Almuñécar con el descubrimiento de jarras similares por W. Andrae (1938:159) en las ruinas de Assur en el Palacio de Assurnasirpal II, donde uno de estos vasos lleva dos interesantes inscripciones, una en egipcio jeroglífico traducida por Fr. W. von Bissing (1940:149-182) que recuerda algunos aspectos de las inscripciones de Almuñécar, y otra en lengua asiria y escritura cuneiforme, donde se proclama su procedencia del saqueo del palacio del príncipe Abdimilkurti, rey de Sidón, por Assharadón, acontecido en el año 677 a. C.

Con esta premisa, W. Culican (1970:31) se pregunta si los vasos de alabastro hallados en Almuñécar, no pudieron formar también parte de los tesoros del palacio de Abdimikurti en Sidón cuando fue atacado por Esarhaddon, de cuyo saqueo se salvarían al ser traídos a Occidente por fugitivos fenicios. Culican ve en esta procedencia una de las vías para explicar el uso de posibles "regalos reales" egipcios como urnas de enterramiento en las tumbas de los refugiados que las transportaron.

Por último es interesante constatar que este mismo tipo de vasos de alabastro se ha documentado en diferentes lugares de Egipto y concretamente en la necrópolis real de Tanis, donde fueron enterrados los faraones de las dinastías XXI y XXII entre los que se encuentran, como ya hemos citado, los faraones cuyas cartelas están inscritas en los vasos de Almuñécar. P. Montet (1947-1960), excavador de esta necrópolis real, documenta vasos de alabastro, tan similares a los del Cerro de San Cristóbal, que resulta difícil no defender esta procedencia. Así mismo existen inscripciones en vasos de alabastro, que proceden con certeza de miembros de la familia real libia, que incluso tienen semejanza con el contenido de las inscripciones de Almuñécar, como la existente en un vaso perteneciente a Horus, hijo de Iputi ${ }^{21}$, en el escondite de Deir el-Bahari, que evidentemente es una ofrenda funeraria, donde también se habla del vino, que "inunda tu casa (o sea la tumba) con alegría, de modo que tú te embriagas día y noche" (Gamer-Wallert 1973:406).

20. No hemos encontrado noticias de saqueos de tumbas a manos de los asirios, pero durante la conquista persa, Herodoto (III,37) cuenta como Cambises mientras permanecía en Menfis cometió locuras como abrir viejas tumbas e incluso examinar los cadáveres. 21. El Cairo, M. Egipcio, CG 18435. 


\section{CONCLUSIONES}

Como conclusión final creemos que para obtener alguna información sobre el vaso de alabastro hallado en la necrópolis del Cerro de San Cristóbal en Almuñécar donde Bes está representado, hay que interpretarlo dentro del contexto de los ejemplares procedentes de este yacimiento, ya que es la gran cantidad, exclusividad, homogeneidad, significado y cronología de los mismos lo que puede darnos alguna pauta para hipotizar sobre su origen, uso y destino.

Basándonos en la diferente información obtenida del conjunto de estas jarras, en primer lugar es obvio que su procedencia es Egipto. En segundo lugar parece plausible que la cronología de su fabricación sea contemporánea a la del faraón mencionado en la cartela que ostenta (874-850), inclinándonos por la fecha más baja, ya que pensamos que su finalidad pudo ser funeraria de acuerdo con las inscripciones aparecidas en otras jarras de la misma procedencia; por último su contenido, vino, también parece estar indicado por estas mismas inscripciones, de tal modo que si admitimos su uso funerario, el vaso contendría una ofrenda de vino para el difunto.

Con este significado la representación de Bes estaría en consonancia con sus funciones como protector del nacimiento en el "Más Allá", como está demostrado en Egipto por su presencia en diferentes objetos en las tumbas, entre los que se incluyen los vasos cerámicos donde se representa su rostro. A pesar de que tanto morfológicamente como en la calidad del material estos vasos no son comparables, podría apuntarse la posibilidad de que en su origen el vaso hallado en Almuñécar fuera un "ejemplar lujoso" realizado para un enterramiento real, con la misma finalidad que los vasos plásticos con representaciones de Bes que se encuentran en tumbas modestas pudieron tener, la ofrenda de un líquido revivificador (por qué no vino) para el difunto. La presencia en las inscripciones de alusiones a la diosa Hathor podría ser una prueba más en este sentido.

Por último si admitimos su uso funerario, este vaso de alabastro, probablemente procedería de una necrópolis de la realeza. La presencia de tipos muy similares de jarras de alabastro en la necrópolis real de Tanis, hace sospechar que ésta podría ser una de sus procedencias. Estas hipótesis nos conducen a la suposición de un expolio de necrópolis de alto nivel, cuyos materiales estarían prácticamente destinados a un comercio canalizado hacia un tipo de compradores interesados en la adquisición de estos bienes de prestigio. La prácticamente ausencia, hasta la fecha, de este tipo de vasos en el mundo colonial fenicio, excepción hecha de la parte del litoral peninsular entre Cádiz y Almuñécar, podría significar que se tratara de un uso muy característico de esta zona. La pregunta subsiguiente sería cuál era el factor diferencial que daría lugar a este fenómeno. Podemos hacer algunas especulaciones, por ejemplo que se tratara de un grupo específico proveniente de una zona concreta etc. Sin embargo, hay un factor que podría justificar esta exclusividad: para el acceso a un material que no era usual, ya fuera proveniente de una actividad comercial anterior o del expolio más o menos contemporáneo de necrópolis egipcias, este grupo tendría que acudir a unos canales que previsiblemente no serían los normales para otro tipo de mercancías, por lo que en nuestra opinión, debería estar conectado muy directamente con estos canales de adquisición y distribución, sino eran ellos los protagonistas de los mismos. 


\section{BIBLIOGRAFÍA}

ALTENMÜLLER, H. (1965): Die Apotropaia und die Götter Mittelägyptens, Eine Typologische und Religionsgeschichtliche Untersuchung der Sogenannten "Zaubermesser " des Mittleren Reichs, 2 Vols. München.

ANDRAE, W. (1938): Das wiedererstanden Assur. Leipzig.

AUBET, $M^{a}$ E. et alii (1991) : Sepulturas fenicias en Lagos (Vélez-Málaga). Sevilla.

BAENA DEL ALCÁZAR, L. (1978): "Fragmentos de vasos de alabastro en yacimientos fenicios de la provincia de Málaga", Anejos de Baetica I: 159-165.

BALLOD, F. (1913): Prolegomena zur Geschichte der Zwerghaften Götter in Ägypten. Moscú.

BISSLG, Fr. W. (1940b): "Agyptische und ägyptisierende Alabastergefässe aus den deutschen Ausgrabungen in Assur", ZA (NF) 12: 149-182.

BRUYÈRE, B. (1939): Rapport sur les fouilles de Deir el Médineh (1934-1935). Le Cairo.

CARTER, H. y MACE, A.C. (1923): The Tombs of Tut-ankh-amen I. London

CINTAS, P. (1970, 1976): Manuel d'Archéologie punique I - II. Paris.

CULICAN, W. (1970): “Almuñécar, Assur and Phoenician penetration of the Western Mediterranean", Levant II: 28-36.

CHARVÁT, P. (1980): “The Bes jug: Its origin and development in Egypt”, ZÄS 107: 46-51.

DRIOTÓN, E. y VANDIER, J. (1962, 1983 Ed. Esp.): Historia de Egipto. Buenos Aires, Eudeba.

FRIEDMAN, F. (1998): Ancient egyptian faience. Londres, Thames \& Hudson.

GAMER-WALLERT, I. (1972): "El vaso canopo de la colección Ramón Fernández Canivell (Málaga)", TP 29: 267-271.

- (1973): "La inscripción del vaso de alabastro de la tumba nº 1 de Almuñécar (Granada)", XII CNA: 401-408.

- (1976): “Die hieroglyphenischrift auf dem alabastergefass in Puerto de Santa María", Habis 7: 223-228. (1978): Äegyptische und ägyptisierende Funde von der Iberischen Halbinsel. Weisbaden.

GARCÍA ALFONSO, E. et alii. (1999): Museos Arqueológicos de Andalucía(II). Almería, Granada, Jaén y Málaga. Macarena, Ed. Ágora.

GARCÍA Y BELLIDO, A. (1970): “Algunas novedades sobre la arqueología púnica-tartesia”, AEArq 43:11-21.

GÓMEZ MORENO, M. (1958): Adam y la Prehistoria. Madrid.

GUIDOTTI, M. C. (1983): "Ipotesi di significato e tipologia dei vasi egizi di epoca tarda raffiguranti il dio Bes", EVO 6:33-65.

HAYES, W. C. (1953): The Scepter of Egypt I. New York.

(1959): The Scepter of Egypt II. Massachussets, Harvard Univ. Press.

JIMÉNEZ FLORES, A. Mª . (1996): Ritual funerario y sociedad en las necrópolis fenicias de época arcaica de la Península Ibérica. Sevilla.

KITCHEN, K. A. (1986): Third Intermediate Period in Egypt (1100-650 B. C). Warminster.

LECLANT, J. (1991): "Les Phéniciens et l'Égypte”, ACFP II Vol. I: 7-17.

LÓPEZ GRANDE, M J. (1988): “Dioses egipcios del Hogar”, RArq $\mathrm{n}^{\circ}$ 91: 12-24.

LÓPEZ GRANDE, M M. et alii. (1995): Excavaciones en Ehnasya el Medina (Heracleópolis Magna) Vol. II. Madrid, Ministerio de Cultura.

LÓPEZ MÁLAX-ECHEVARRÍA, A. (1971-73): "La necrópolis púnica El Jardín”, Malaka 6: 29-40.

MALUQUER DE MOTES, J. (1963): “La necrópolis de Sexi”, Zephyrus XI: 57-62.

MOLINA FAJARDO, F. y PADRÓ I PARCERISA, J. (1983): "Nuevos materiales procedentes de la necrópolis del Cerro de San Cristóbal (Almuñécar, Granada)", Ampurias 45: 284-293. 
MOLINA, F. y BANNOUR, A. (2000): “Almuñécar a la luz de los nuevos hallazgos fenicios" ACFP IV: 1645-1664.

MOLINERO POLO, M. A. (1995): "Recipientes de piedra" en Ma J. López Grande et alii, Excavaciones en Ehnasya el Medina, Vol. II, Parte II: 205-277.

MONTET, P. (1947-1960): La nécropole royale de Tanis. Paris. 3 Vols.

NEGUERUELA, I. (1985): "Sobre la fecha de la necrópolis "Laurita" de Almuñécar", NarqH 22: 193-210.

_ (1991): "La necrópolis fenicia "Laurita" de Almuñécar". IV Jornadas de Arqueología fenicio-púnica: 199-204. Ibiza.

PADRÓ I PARCERISA, J. (1978): "El deu Bes: Introducció al seu estudi”, Fonaments 1: 19-41.

- (1983): "Las inscripciones egipcias de la Dinastía XXII procedentes de Almuñécar (Granada)", AO 1: 215-226.

- (1984): "Materiales egipcios del Cerro de San Cristóbal (Almuñécar, Granada). Hallazgos de la campaña de.1963”, en F. Molina (ed.), Almuñécar Arqueología e Historia, II: 11-78.

(1985): Egyptian-Type Documents from the Mediterranean Littoral of the Iberian Peninsula before The Roman Conquest. Vol. III Study of the material. Andalusia. EPRO, 65. Leiden.

(1986): "Las importaciones egipcias en Almuñécar y los orígenes de la colonización fenicia en la Península Ibérica", Homenaje a Luis Siret: 526-529. Sevilla.

(1995): New egyptian-type material, OrMonsVIII. Montpellier.

PEET, E. y WOOLLEY, L (1923): The city of Akhenaten. London.

PELLICER CATALÁN, M. (1963): Excavaciones en la necrópolis púnica "Laurita" del Cerro de San

Cristóbal (Almuñécar, Granada). EAE 17. Madrid.

PÉREZ DIE, Ma C. (1976): "Notas sobre cuatro vasos egipcios de alabastro procedentes de Torre del Mar

(Málaga) conservados en el M.A.N.", RarchBibMus LXXIX: 903 -918.

- (1983): "Un nuevo vaso egipcio de alabastro en España”, Homenaje al Profesor Martín Almagro Basch Vol. II: 237-244.

- (1992): Heracleópolis Magna durante el TPI. Tesis doctoral reprografiada. U.C.M. 303/92. Madrid. PETRIE, W.M.F. (1974 reimp.): Illahum, Kahum y Gurob. London.

ROMANO, J.F. (1989): The Bes-Image in Pharaonic Egypt. Doctoral dissertation, New York University. SCHUBART, H. y NIEMEYER, H.G. (1976): Trayamar. Los hipogeos fenicios y el asentamiento en la desembocadura del río Algarrobo. EAE 90.

SETHE, K. (1932-33): Urkunden des Alten Reichs. Leipzig.

WRESZINSKI, W. (1988): Atlas zur Altaëgyptischen culturgeschichte I. 


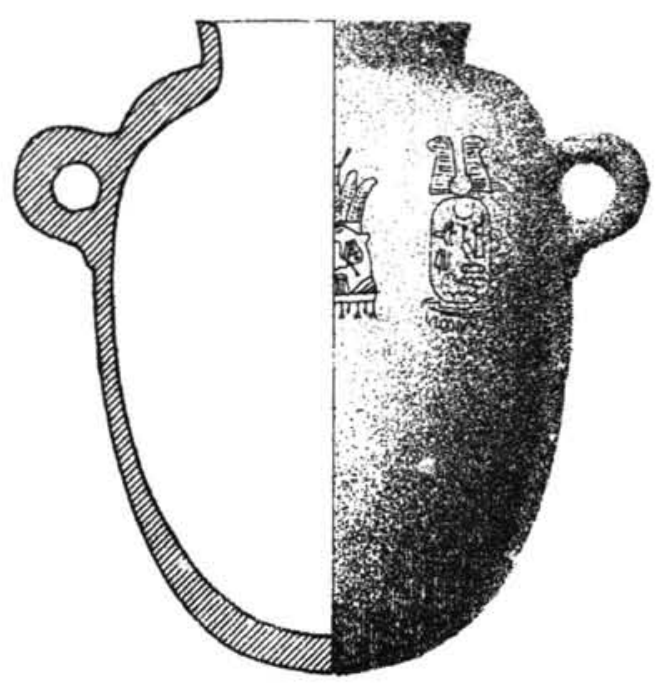

Fig. 1 Dibujo del vaso de alabastro procedente de la tumba $\mathrm{n}^{\circ} 17$ de la necrópolis del Cerro de San Cristóbal (Almuñécar, Granada). Granada MAP 8332. Pellicer 1963:31 fig. 26,1. Dinastía XXII.

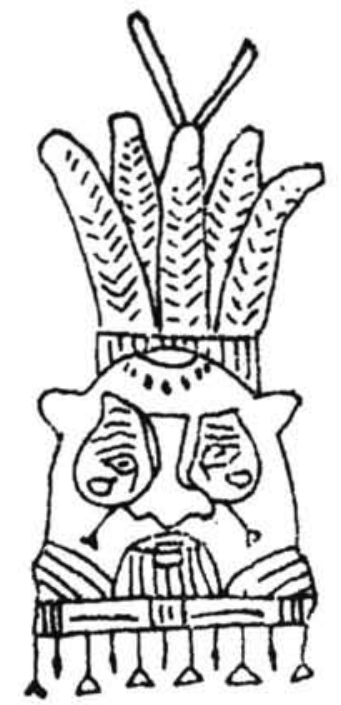

Fig. 2 Dibujo del rostro del dios Bes representado en el vaso de alabastro de la tumba $\mathrm{n}^{\circ}$ 17. Pellicer 1963:32, fig. 26,2 .

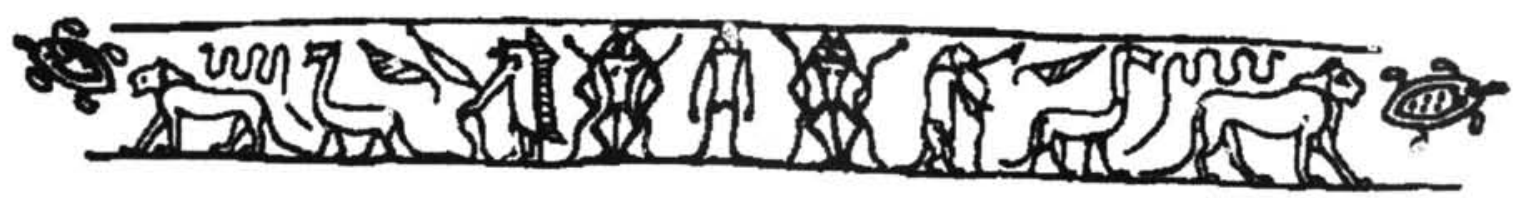

Fig. 3 Desarrollo del dibujo representado en un "biberón" procedente de Lisht. New York, MMA 1944. 44.4.4.F. Friedmann 1998:207 nº 67, fig. 48. Imperio Medio. 


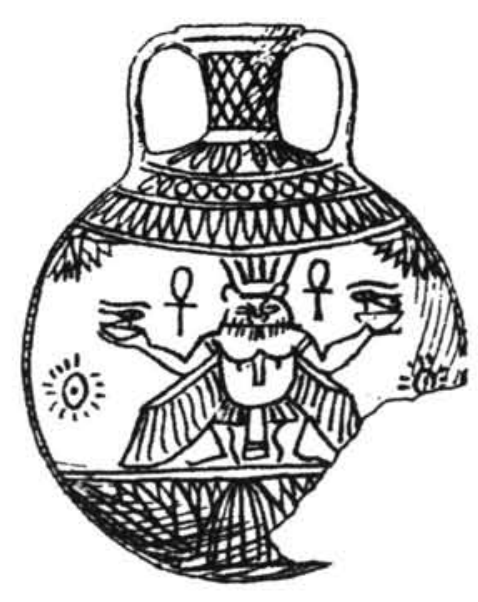

Fig. 4 Vaso procedente de Gurob. Oxford, Ashmoleam Museum, 1890.897. Petrie 1974 (reimp.): lám. XVII, 9. Dinastía XVIII.

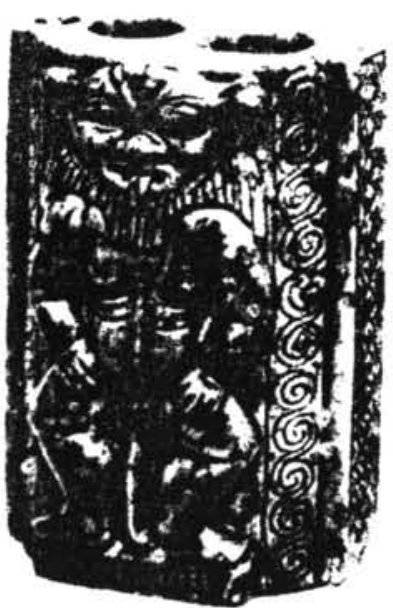

Fig. 5 Contenedor de cohol, procedencia desconocida. Col. Carnavon. Hayes 1959: 192, fig. 107. Dinastía XVIII.

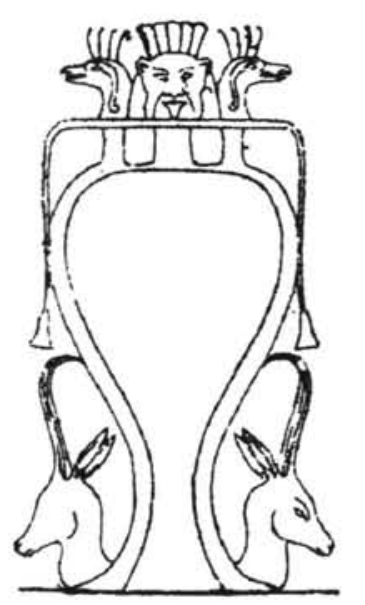

Fig. 6 Vaso con tapadera en forma de cabeza de Bes, existente en un relieve del templo de Seti I en Karnak. Ballod 1913: 50, fig. 47. Dinastía XIX.

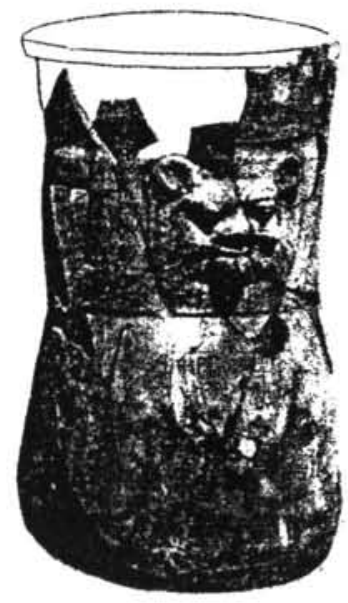

Fig. 7 Vaso con cabeza de Bes procedente de Deir el-Medina. Bruyère 1939:102, fig. 35. Dinastía XVIII.

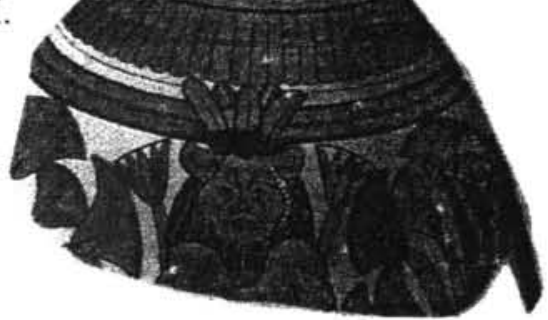

Fig. 8 Vaso con dibujos de Bes procedente de Amarna. Peet y Woolley 1923 lám. XLV, fig. 4. Dinastía XVIII.

ISSN: 1133-4525 ISSN-e: 2255-3924 http://dx.doi.org/10.12795/spal.2002.i11.05 


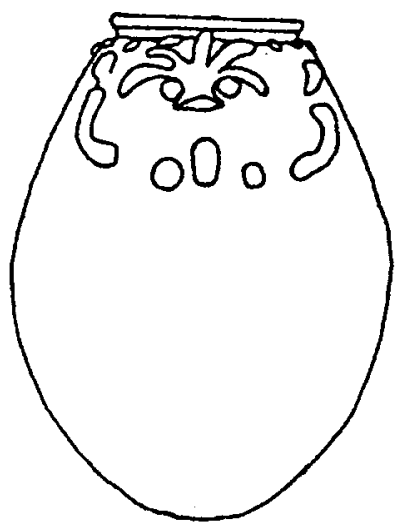

Fig. 9 Vaso con representación de Bes de procedencia desconocida. Guidotti 1983: 41 fig. 3 (tipo A). Tercer Período Intermedio.

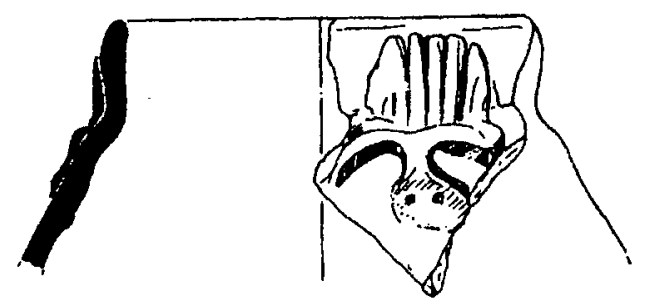

Fig. 11 Vaso con representación de Bes procedente de Enashia el-Medina. López Grande $e t$ alii 1995:60. Tercer Período Intermedio.

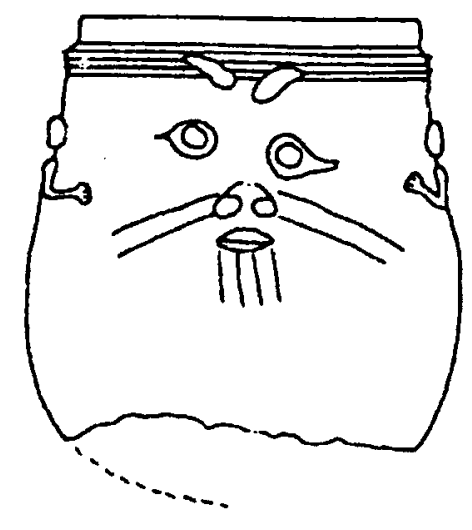

Fig.10 Vaso con representación de Bes procedente de Qurna. Guidotti 1983:46 fig. 7 (tipo B1). Tercer Período Intermedio.

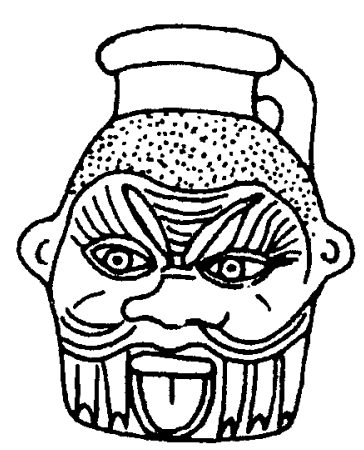

Fig. 12 Vaso plástico de Bes procedente de El Fayum. Guidotti 1983:57 fig. 84 (tipo C). Período Grecorromano. 